\title{
Ten Years of Enhancing Engineering Education with CaSe STUDIES: INSIGHTS, LESSONS AND RESUlTS FROM A DESIGN CHAIR
}

\author{
Steve Lambert *, Cheryl Newton**, and David Effa *** \\ Waterloo Cases in Design Engineering, University of Waterloo, Waterloo, Ontario, Canada \\ Mechanical and Mechatronics Engineering, University of Waterloo

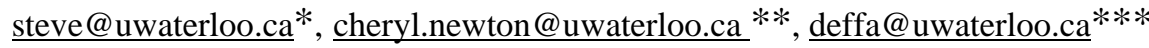

\begin{abstract}
Improving student learning and increasing connections between theory and engineering practice captures the main goals of Waterloo Cases in Design Engineering (WCDE). WCDE is a group at the University of Waterloo (Waterloo) that was established in 2005 as a part of the NSERC Chairs in Design Engineering program. WCDE works with instructors, industry and students to bring real life complexities to the classroom by using authentic case studies. Over the last ten years, more than 175 case studies have been developed and implemented in more than 100 courses with over 125 instructors, across all engineering disciplines. WCDE has collaborated with more than 140 industry, government, non-profit, and academic case partners for the development and implementation of case material.

Surveys are used to gange students' receptivity to case implementations and for continuous improvement. Student feedback from WCDE case implementations are presented and discussed. The benefits and challenges of case study teaching are discussed, along with reflections on the next steps towards extensive use of engineering cases in education.
\end{abstract}

Keywords: Case Study; Active Learning; Engineering Education; Experiential learning

\section{INTRODUCTION}

Case studies have long been recognized as an excellent pedagogical tool to develop critical thinking skills in engineering undergraduates [1-4]. However, aside from failure-based cases [5], available cases involving common engineering practice are few. The Waterloo Cases in Design Engineering (WCDE) group was formed to address this need [6-10]. WCDE was created through the Natural Sciences and Engineering Research Council (NSERC) Chairs in Design Engineering program, with the support of the University of Waterloo (Waterloo) and key industrial partners: including General Motors of Canada Limited, Blackberry, Hatch, Christie Digital, AMEC, Multimatic Technical Centre, and Babcock and Wilcox Canada. WCDE's mission is to improve student learning, to help students make connections between theories and engineering practice, and to help students appreciate and deal with the complexity of real engineering challenges. To achieve this goal, WCDE generates and implements engineering case studies for use throughout the engineering curriculum.

The group consists of two full-time engineering designers, co-op students, and supported by various stakeholders from industry, university administration, faculty and students. Three key committees include the Industrial Advisory Committee (IAC), the Design Champions Committee (DC), and the Student Advisory Committee (SAC). These committees provide strategic guidance, operational assistance, and feedback for continuous improvement of our cases, their implementation, and our operational activities.

WCDE has made significant progress over the past 10 years developing a wide range of engineering cases that illustrate real-world applications of engineering concepts. The case studies developed by WCDE concisely capture an engineering experience, and allow that experience to be used to facilitate the application of theories, concepts and knowledge to an engineering challenge. WCDE develops these cases from a broad range of sources including co-op experience, design projects, literature sources, and the experience of industry professionals $[6,8,10]$. The main focus has been on leveraging Waterloo's co-op program to generate case studies from student experience (work term reports), and allow others to learn from this experience. In addition to case development, WCDE provides teaching resources such as presentations, simulations and multimedia material, and guidance on the effective use of cases. WCDE has delivered more than 30 case teaching and writing workshops for instructors and students.

This paper discusses WCDE case study practice, results, and reflections.

\section{WCDE CASE DEVELOPMENT AND IMPLEMENTATION APPROACH}

Waterloo operates the largest post-secondary co-op program in the world. All engineering students participate in the co-op program, providing a vast potential of real- 
world engineering experience which can be used in the classroom to foster in-depth learning and reshape the traditional classroom environment. WCDE is tapping this vast resource to generate engineering cases that provide an opportunity for students to experience the complexity of engineering problems and develop their own solutions, allowing them to make connections with material in their curriculum, and gain an appreciation of the breadth of knowledge and experience required to solve real problems [11].

\subsection{Case Development}

WCDE modelled our case development process after well-established practices for business cases at the Ivey School of Business [7, 12]. Initially, focus was on developing cases from work term reports (case source) which were recommended by work report markers, and matching those to instructor (case receptor) requirements. As the group gained more experience and expanded case source material (to include student capstone projects, literature material, and interviews with practicing engineers) we were better able to respond directly to instructor requests.

The WCDE case development process [10] begins by identifying engineering concepts with a wide impact, assessing instructor requirements for learning objectives, and matching them with available source material. These are presented in a formal case plan, which consists of an opening paragraph to capture the essence of the situation, learning objectives, and case structure. WCDE case structure includes the case itself and various solution modules, which are typically not released to students. The case itself presents the problem in detail, context and requirements, and includes most of the data to enable students to solve the problem on their own. Sometimes, specific data is held back to give students the opportunity to identify the solution approach and specific data requirements. Separate modules present the solution, if available, although it is emphasized that for any engineering problem, different approaches are possible. All data and analyses to be used in the case and the modules are listed in the case plan so that stakeholders can make an informed decision about whether to, and how, to proceed with case development.

The case plan allows stakeholders to provide feedback on case structure and content, and for the industry partner (typically the work term employer) to better understand what data and analyses are to be released at the completion of the process. Decisions can be made at this point whether to go ahead as planned, to disguise the case source, scale data to protect proprietary information, or abandon the case. Once the case plan is provisionally released, WCDE staff write the case, review it internally, and then distribute it to the employer for final approval and case release.
Figure 1 illustrates the current distribution of cases, classified according to the target Department, Mechanical and Mechatronics Engineering (MME), Systems Design Engineering (SYDE), Architecture (ARCH), Business and Entrepreneurial Technology (BET), Chemical Engineering (CHE), Civil (CIVE) and Environmental (ENVE) Engineering, Electrical and Computer (ECE), Software (SE) Engineering, and Management Sciences (MSCI) Engineering. Nanotechnology Engineering cases are included with CHE, Biomedical Engineering cases are included with SYDE, and Geological Engineering cases are included with CIVE. Of course, cases are also promoted for use outside their nominal target Department.

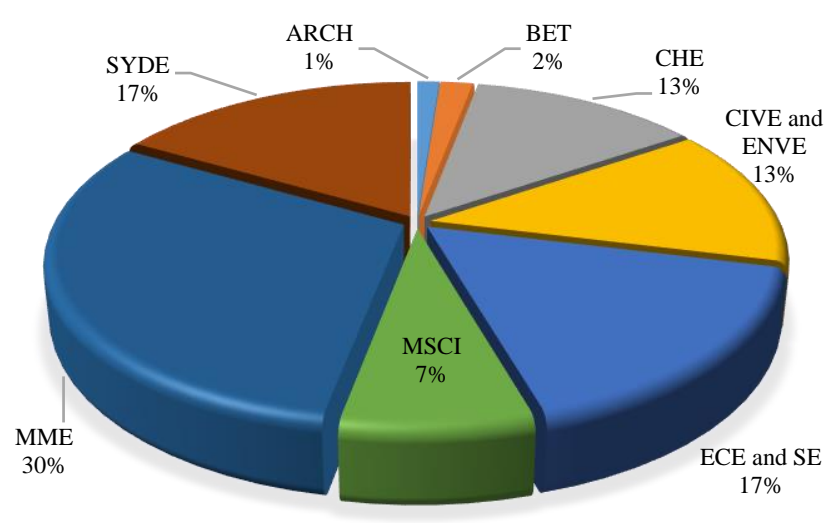

Fig. 1. 2016 WCDE Case Distribution

WCDE supports case implementation through the production of presentations, providing guidance specific to each case, and one-on-one discussions with instructors. Once a case has been implemented, support materials are cataloged and can be provided to instructors in subsequent terms.

The authors of the case include the WCDE staff as well as any authors of the original case material. They own the copyright and license it to Waterloo for use in education. The case must be formally released by the appropriate company representative, and about $2 / 3$ of our cases are released for use outside of Waterloo.

With a critical mass of 175 available cases, WCDE is focusing more and more on classroom implementation. Currently, the case development focus has shifted to first identify a particular case receptor and appropriate case learning outcomes.

2.1.1 What makes a good Case? All cases must have real context, real data and/or information and appropriate engineering design and/or analysis. Beyond that, WCDE has developed the following additional guidelines for prioritizing case development for maximum impact.

- Cases must be current and suited to the level of the students. 
- The case must provide the opportunity for students to complete a useful pedagogical engineering activity, ideally beyond a straight-forward engineering analysis. This could include offering learning opportunities for problem finding, teamwork, project management, economics, and communications, for example, in a realistic context of engineering analysis and/or design.

- Cases should involve a problem or situation that motivates students to explore, investigate and study.

- The case should involve an application that will engage and energize students, which helps to foster discussion and enhancing interaction between students and their peers, as well as with the instructor.

- Case should provide the opportunity to investigate material from different perspectives, and so integrate concepts across a discipline and between disciplines.

\subsection{Implementation approaches}

WCDE cases have been used in various forms including as in-class examples, assignments, quizzes, as the basis for group and class discussions, and/or as projects. The choice of teaching method is up to the individual instructor and is based on the learning objectives, the resources and time available, and how the case aligns with course material. Typical case implementation activities include professor planning, individual preparation by students, small group discussion, classroom discussion, and perhaps a follow up assignment. This succession of discussion encourages students to take responsibility for their own learning, gives them some freedom to focus on areas of personal interest, while forcing them to make judgments regarding learning strategies, and to learn more deeply.

Figure 2 summarizes case implementations over the past 5 years. Over 175 implementations have occurred, across all Departments, from first year to the graduate program.

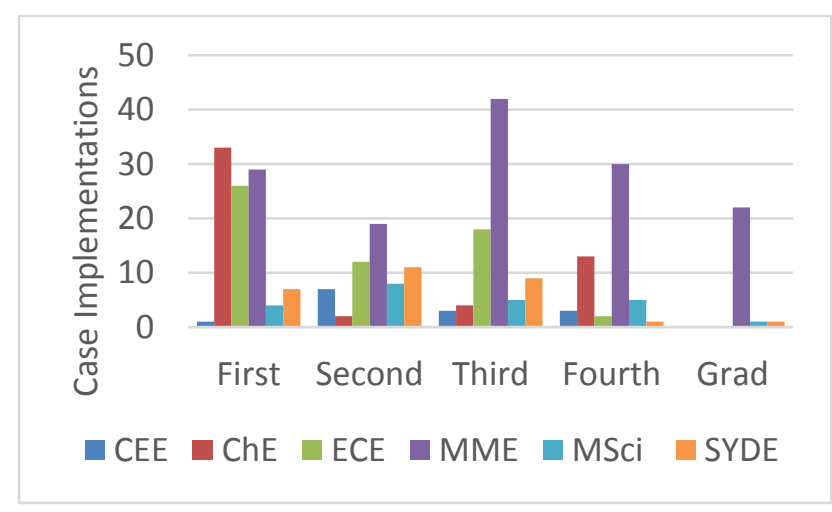

Fig. 2. 2010-2015 WCDE Case Implementations
After case implementation, case storyboards are created to illustrate different case implementation strategies, to identify best practices, and to promote the effective use of cases [13].

\section{STUDENT AND INSTRUCTOR FEEDBACK}

Feedback is regularly solicited from students and instructors following case implementations. Student feedback provides insight on case teaching methods, student learning, and case quality. Responses from 12 courses in four departments, for a total of 854 students, were aggregated in the following survey feedback. Students were asked to respond to five questions on a Likert scale, from strongly disagree to strongly agree. The number of respondents for each question differs based on the course offering. Figure 3 shows the student response to one question: "This case study was an engaging application of these specific course topics". The majority of students, $87 \%$, either agreed or strongly agreed with this statement. Students have been excited about seeing realworld applications of engineering theory throughout their curriculum. This helps with student motivation to study course material.

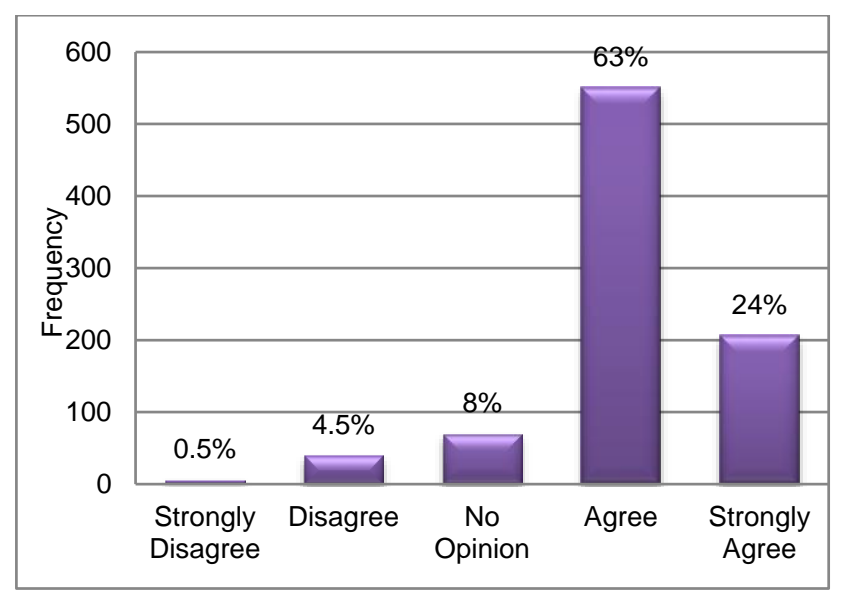

Fig. 3. Student response to the question: "This case study was an engaging application of these course topics".

Another question explored the connection between the case and the course material: "This case study improved my appreciation for the relevance of these specific course topics". Similar results were obtained, $78 \%$ agreed or strongly agreed with this statement. The value of a strong connection between the theoretical concepts discussed in class and a real-world practical case study was evident.

Students were asked about their perception of their understanding of the material: "This case study helped me understand these specific course topics". The percentage of students who agreed or strongly agreed was $71 \%$. Students appreciated the application of course material but commented that a closer connection was desired. One motivation for using cases is to get students to step back 
and see a wider perspective outside of immediate course material, tying strength analysis to manufacturability and economics, for example.

An important element of the case method is small group discussions; getting students to learn from each other. Students were asked about the statement: "Small group discussions of the case helped me understand the specific course topics". Figure 4 shows the distribution of responses for this question. The number of students who either agreed or strongly agrees was $81.5 \%$. Feedback relating to this question included the fact that the discussions "created an interactive environment with classmates" and "helped to clear the doubt and solved problems that couldn't be solved sitting alone." The number of neutral or negative responses could be attributed to a lack of time available for small group discussion or no small group discussion at all. To get the most out of the case method learning approach, more time is required for discussion. In business school applications, students are more familiar with the case approach and are trained to have these small group discussions before class with peers, so that class time can be devoted to full class discussions. This is not always feasible where students only use one or two cases in a term. This means that more class time should be set aside for small group discussions, which requires the removal of some course content or employing a strategy such as a flipped classroom.

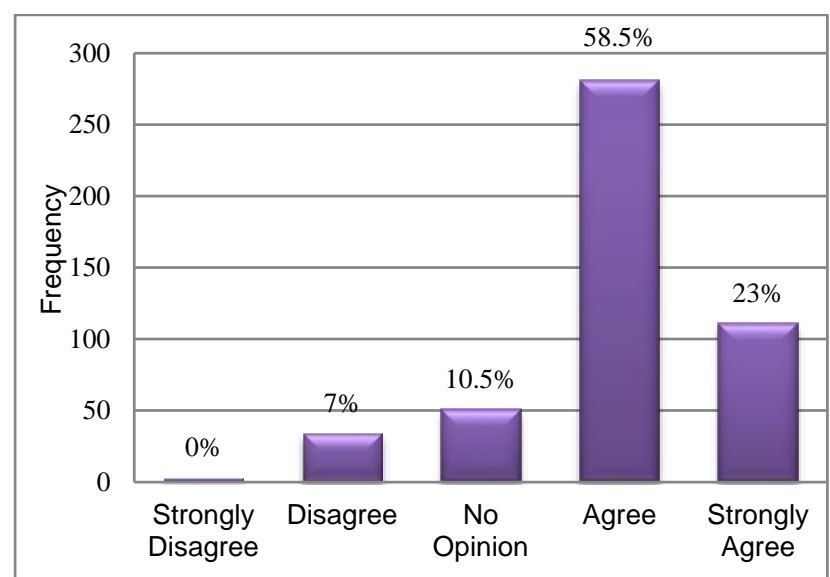

Fig. 4: Student response to: Small group discussions of the case helped me understand the specific course topics

Students also provided general feedback for improvement of the case study and case activities. Some respondents suggested different time allocations. Although we encourage the students to review the case prior to class, it is normal to present the case and guidance on how to proceed. Some suggested that this should be cut back, including the presentation of background material. Others suggested that the case should be introduced earlier in the term to allow time for more guidance on what was expected. This would make the discussions more efficient.
Some requested a more challenging problem, while others suggested a more open-ended topic, with less detail provided, to provide more scope for discussion. These are all very positive in terms of how students are responding to the case method.

WCDE also solicits feedback from instructors in order to improve the impact of engineering cases, and better coordinate with existing teaching activities. We have had very positive response from instructors, who welcome the opportunity for students to learn using realistic problems. Instructor's value the case support material produced by WCDE and especially the customized assistance for case use and development.

\section{LESSONS LEARNED}

WCDE has made considerable progress related to the process of case writing and implementation. Generally, there is consistent and enthusiastic buy-in from students, industry, and instructors. There is still some difficulty making case use pervasive within Waterloo, and beyond. We have worked to minimize barriers to participation and to ensure that there is a diverse portfolio of sources and routes for case development. The following are some of the lessons learned over the past 10 years.

The case method engages students and helps to bridge the gap between academy and industry

The use of cases in engineering courses has been shown to engage students and help them to better understand course material. A variety of case implementation strategies have engaged students in the course material and helped them to gain a broader perspective, integrating material from different courses. We formed the Student Advisor Committee explicitly to respond to student enthusiasm for cases.

\section{A strategy is necessary to overcome resistance to change}

Bringing such a paradigm shift at any institution is a challenge, and our experience at Waterloo is no different. The use of cases requires a significant change in the culture of teaching. Overcoming resistance is in some case perhaps the most difficult barrier that WCDE faces. Some of our observations with regards to instructor resistance to change include:

- Courses are already very heavy and there is no space to introduce new course content

- Instructors tend to be independent, and are skeptical about making significant changes to the way in which they deliver their courses.

- Instructors are experts in their own area, but lack experience with the specific case study topics and are unfamiliar with the case method 
- Instructor limited time available to devote to teaching (and their own learning) may result in them being under-prepared to use the case effectively

- Large class sizes and the physical structure of classrooms make it difficult to facilitate class case discussions.

\section{Difficult to find the 'right' cases}

WCDE has made a concerted effort to generate over 175 cases to date. However, the diversity of engineering over 13 programs makes it difficult to find the best fit for cases in a particular course. There is an ongoing need to modify cases, and produce more cases, especially shorter cases to get cases adopted in more courses, and for the first time user.

\section{Effective assessment models are required}

Assessing the impact of cases over a wide range of courses is very difficult, and depends strongly on the course material. We have relied strongly on student feedback, and more work is required to assess student learning. These will require more collaboration with faculty members and the use of control groups [14].

\section{Strong collaboration with instructors is required}

Collaboration with instructors and various groups within the University, especially the Centre for Teaching Excellence, is vital for the success of any teaching innovation. This helps to increase case uptake and maximize the value of case method. WCDE has developed significant collaborations with instructors both for the development and implementation of case studies, and worked with CTE in the development of case writing and teaching workshops. Increasingly, instructors co-author cases in collaboration with WCDE. The group needs to focus more on facilitating case writing by instructors themselves, as is done business schools, to promote sustainable case development and implementation.

\section{Expansion beyond Waterloo is now necessary}

WCDE provides cases to instructors from other Universities based on individual requests. However, the group would like to develop meaningful partnerships with other Universities moving forward. A framework to make cases more readily available outside of Waterloo is necessary. We are currently exploring options for partnerships, which include options for both case development and sharing.

\section{Effective promotion is required}

Due to the nature of the academic environment, group promotion is critical and must be done on a continuous basis. Furthermore, expanding WCDE's impact requires effort to disseminate and share its products outside of engineering and the University. The group to date has not focused resources to develop a strong marketing and promotional strategy. However, in the past year significant effort has been done to address this issue.

\section{More Diverse case options are required}

The initial focus for this program was on cases developed from work term reports. Although successful across a range of concepts and disciplines, this resulted in a narrow case structure: relatively long cases which were more difficult to introduce into courses already packed with material. Recently, there has been more emphasis on developing cases to order, including shorter cases and cases from the literature to reflect topical events, such as the Vancouver port chemical fire and the VW emissions scandal.

\section{Strong administrative support is required}

Managing the case collection and requests for cases would be more efficient with appropriate administrative support. This has not been a priority but must be addressed moving forward.

\section{Sustainability of the program}

WCDE has received strong funding through NSERC's Chairs in Design Engineering program, and support from the University and industry. We must now work to develop a sustainable funding strategy without NSERC support.

\section{Expanded case services}

In addition to formal WCDE cases, there is a strong demand for customized case development and case support for instructors. These are not always published as WCDE cases, but make a valuable contribution to the curriculum. In 2015 alone, 84 case support activities were undertaken by the group in the following areas: significant instructor interaction, customized cases, case modifications, case implementation support, clinic activity support, and joint publications [15].

\section{NEXT STEPS}

To maximize the potential of case studies throughout the curriculum, a sufficient quantity and quality of diverse cases of appropriate scope must be generated and maintained. To make this happen, WCDE must encourage and work with instructors interested in preparing their own case study material. WCDE should also work to overcome barriers by demonstrating value to all stakeholders. This must come with a recognition of the value of all improvements to student learning. All must see the value of the overall approach, and all must participate in a different capacity. 
The group should also focus on continuous improvement of its online environment to support case distribution and feedback, to improve efficiency. While some cases include hardware exhibits and hands-on activities, this has not been a focus. The group has instead worked closely with the IDEAS clinic to support and leverage their hands-on activities [16].

Enhancements to the currently available case writing and teaching workshops is necessary to promote case development and use throughout and outside the University. Having faculty write their own cases and make them available through WCDE to others, as is done in business schools, is an important requirement for a sustainable program to use cases throughout engineering. This will be a cornerstone for partnering with other Universities in the development and use of cases.

\section{References}

[1] M.J. Prince and R.M. Felder, "Inductive teaching and learning methods: Definitions, comparisons, and research bases", Journal of Engineering Education 95, 3, 123-38.

[2] P.K. Raju and C.S. Sankar, "Teaching Real-World Issues through Case Studies", Journal of Engineering Education 88, 4, 501-08.

[3] K. Garg and V. Varma, "A study on the Effectiveness of Case Study Approach in Software Engineering Education", Proceedings of $20^{\text {th }}$ Conference on Software Engineering Education and Training, Dublin, Ireland, 2007.

[4] Richards, L.G., and Gorman, M.E., Using Case Studies to Teach Engineering Design and Ethics, Proceedings of the 2004 American Society for Engineering Education Annual Conference and Exposition, paper 992.

[5] H. Petroski, "To Engineer is Human: The Role of Failure in Successful Design”, Vintage Books, 1992.

[6] S. Lambert, C. Campbell, and O. Nespoli, "Leveraging Student Co-op Design Experience Using Case Studies", International Conference on Engineering and Product Design Education, Universitat de Catalunya, Barcelona, Spain, 4-5 September, 6 pages (2008).

[7] Engineering Cases, https://uwaterloo.ca/engineering-cases

[8] S. Lambert and O. Nespoli, "Building a Foundation for Multidisciplinary Design Using Case Studies", Transforming Engineering Education: Creating Interdisciplinary Skills for Complex Global Environments, Dublin, Ireland, April 6-9, 2010.

[9] S. Lambert and O. Nespoli, "Reflections on the use of Case Studies in the Teaching of Engineering Design", International Conference on Engineering and Product Design Education, Dublin, Ireland, September 5-6, 2013.

[10] O. Nespoli and S. Lambert, "Engineering Design Case Studies: Effective and Sustainable Development Methods", American Society of Engineering Education 2010
Annual Conference and Exhibition, Louisville, Kentucky, 2023 June, 2010.

[11] W. Melek, G.D. Stubley, O. Nespoli, and S. Lambert, "Use of Cases in Teaching Engineering Design Workshop for Undergraduate Students", Canadian Engineering Education Association Inaugural Conference, Kingston, Ontario, Jun $7-$ 9, 2010.

[12] L.A. Mauffette-Leenders, M.R. Leenders, and J.A. Erskine, "Writing Cases", Richard Ivey School of Business.

[13] Case Storyboards, https://uwaterloo.ca/engineeringcases/cases/case-storyboards

[14] L. Stacey, A. Unger, M. Ioannidis, and S. Lambert, "Integrating Engineering Science and Design: Case Study Development for a First Year Engineering Science Course", Proceedings of the Canadian Engineering Education Association (CEEA15) Conference, McMaster University, May 31-June 3, 2015.

[15] Case Support Activities, https://uwaterloo.ca/engineeringcases/cases/case-support-activities

[16] L. Stacey, A. Trivett, J. Rathlin, and K.W. Choi, "Implementation of a Case Study in an Engineering Science Course", American Society of Engineering Conference, Seattle, Washington, June 14-17, 2015, paper 902. 